\title{
Color and Fastness Properties of Woven Stretchable Fabrics
}

\author{
Najwa Ali Abu Nassif
}

Fashion Design Department, Design and Art College, King Abdul Aziz University, Jeddah, Saudi Arabia

\begin{abstract}
Stretchable fabrics have gained much interest in the last few years because their higher comforts and aesthetic properties. The main parameters which control the stretchable fabric properties were found to be spandex linear density and draft ratio. In this research paper, the influences of these variables on color properties of stretchable fabrics were investigated. Color properties of the stretchable fabrics were characterized by whiteness index, K/S values, and colorfastness to washing, rubbing and perspiration. The results of this work showed that color properties of the stretchable woven fabrics were affected by independent variables. Generally, impact of spandex draft ratio on color properties was more pronounced than the effects of spandex linear density.
\end{abstract}

Keywords: Stretchable fabrics, Spandex, Draft ratio, Linear density, Color strength, Whiteness index.

\section{INTRODUCTION}

Woven fabrics are used in many different types of clothes such as pants, shirts, dresses, suits and jackets. Woven fabrics provide better physical and aesthetic properties than their knitted counterparts, but they do not physically fit to the human body, due to low stretch properties. In recent years, increasing the stretch properties of woven fabrics was implemented using core-spun yarns containing spandex [1]. In recent years, core-spun yarns containing spandex is widely used to raise stretch characteristics of woven fabrics [1].

Nowadays, stretchable fabrics have gained a considerable attention due to it's widely use in garment industries and the demand for these products is increasing day by day because of their wear comfort characteristics [2]. The main constituent of this type of fabrics is the stretchable yarns which are woven either in one or two directions, i.e. warp and/ or weft direction. The stretchable yarns are composed of core and sheath. The core is mainly made up of multifilament or monofilament of spandex; and the sheath is manufactured from a natural or synthetic staple fibers. Generally, these stretchable yarns are produced using core spinning on different spinning techniques [3-7].

Spandex is a manufactured fiber in which the long chain synthetic elastomer is considered the fiber forming substance that consists of at least eighty five percent by weight of segmented polyurethane. Various chemistries have been evaluated for spandex in the last few years; only polyester and polyether are still in use today. The various production process such as, dry

*Address correspondence to this author at the Fashion Design Department, Design and Art College, King Abdul Aziz University, Jeddah, Saudi Arabia; E-mail: drnagwa20170@gmail.com spinning, wet spinning and melt spinning were used to produce elastane with different tensile properties and cross-sectional geometry [8-10].

Stretchable fabrics are characterized by high extensibility, good dimension stability, high recovery and easy care [11]. Thus these fabrics can be used for sport, hosiery, leisure clothes, underwear and swimwear [12].

Extensive research studies were focused on physical properties of stretchable knitted fabrics [1315]; while a few of them were concentrated on the properties of woven stretchable ones [16-20].

In the light of the above aspects and to my knowledge, there is no a research work concerning the color properties of stretchable woven fabrics made from cotton and spandex with different draft ratios and linear densities. This paper sheds light upon the impact of spandex monofilament key parameters on the color properties of bleached and colored stretchable woven fabrics.

\section{MATERIALS}

Throughout this study, twelve cotton woven fabrics containing spandex were produced. Warp yarn in each fabric sample made up of $100 \%$ Egyptian cotton of type Giza 86 with a net count $30 \mathrm{Ne}$. Weft yarns are composed of spandex monofilament with four different of spandex linear densities, i.e. 20, 40, 60 and 80 denier. Each spandex monofilament was subjected to three different draft ratios, i.e. $3 \%, 4 \%$ and $5 \%$ respectively. All weft yarns were spun into count of 30 $\mathrm{Ne}$ on Sinzer spinning machine. The amount of spandex in each weft yarn was estimated using the following equation: 


$$
P \%=\frac{\text { Spandex count }(\text { Tex })}{D \times T_{y}} \times 100
$$

Where,

$\mathrm{P}=$ Percentage amount of spandex $(\%)$,

$D=$ Draft ratio of spandex (\%), and

$T_{y}=\quad$ Net count of cotton/spandex composite yarn.

Levels of draft ratios and their corresponding spandex amount in the spun weft yarns are listed in Table 1.

Table 1: Spandex Draft Ratios and its Amount in the Weft Yarns

\begin{tabular}{|c|c|c|}
\hline $\begin{array}{l}\text { Spandex count, } \\
\text { Denier }\end{array}$ & $\begin{array}{c}\text { Draft ratio, } \\
\%\end{array}$ & $\begin{array}{l}\text { Spandex } \\
\text { amount, \% }\end{array}$ \\
\hline \multirow{3}{*}{20} & 3 & 3.76 \\
\hline & 4 & 2.82 \\
\hline & 5 & 2.26 \\
\hline \multirow{3}{*}{40} & 3 & 7.5 \\
\hline & 4 & 5.64 \\
\hline & 5 & 4.5 \\
\hline \multirow{3}{*}{60} & 3 & 11.2 \\
\hline & 4 & 8.3 \\
\hline & 5 & 6.7 \\
\hline \multirow{3}{*}{80} & 3 & 15.04 \\
\hline & 4 & 11.28 \\
\hline & 5 & 9.02 \\
\hline
\end{tabular}

All fabric samples were woven on Tsudakoma AirJet weaving machine with speed $430 \mathrm{rpm}$, and warp and weft densities are 31 ends/cm and 27 picks $/ \mathrm{cm}$ respectively.

\section{FABRIC TREATMENTS}

After weaving, greige fabrics were subjected to different wet treatments such as, desizing, scouring, bleaching and dyeing respectively. Desizing is a process of removal of sizing materials from the woven fabrics. It is generally reported that sizing materials has to be removed completely in order to achieve satisfactory levelness of scouring, bleaching and dyeing operations. This process will be executed by dipping the woven fabrics in a hot water at $90{ }^{\circ} \mathrm{C}$. For scouring process, woven fabrics were passed in a solution consists of 30 grams per liter caustic soda $(\mathrm{NaOH}), 2$ grams per liter sequestering agent, 10 grams per liter wetting agent and 2 grams per liter detergent. Process curve for scouring is shown below (Figure 1).

The scoured cotton fabrics were put into bleaching path containing hydrogen peroxide solution $(20 \mathrm{~g} / \mathrm{l}), 2$ $\mathrm{g} / \mathrm{l}$ of sodium hydroxide, $3 \mathrm{~g} / \mathrm{l}$ of organic stabilizer (Sodium silicate) and $1 \mathrm{~g} / \mathrm{l}$ of wetting agent at liquor ratio $50: 1, \mathrm{pH}$ equals 10 and a temperature of $90{ }^{\circ} \mathrm{C}$ for one hour. The bleached fabrics were washed twice in boiling water for 5 minutes to clean any residual chemicals, and then rinsed with distilled water at room temperature.

After bleaching, the woven fabrics were dyed by using reactive dye. The dye bath contains $0.5 \%$ of Ramazol Blue R special dye, $13 \mathrm{~g} / \mathrm{l}$ liquid soda ash (Sodium carbonate $\mathrm{Na}_{2} \mathrm{CO}_{3}$ ) and $50 \mathrm{~g} / \mathrm{l} \mathrm{NaCl}$. The dyeing procedure was executed at a temperature of $60{ }^{\circ} \mathrm{C}$ and time of $60 \mathrm{~min}$. The salt is added to obtain evenness of color throughout the fabric and soda ash is added to fix the color in the fabric.

\section{LABORATORY TESTING}

Before testing, all fabrics were laid in a conditioned and standard atmosphere for one day. Ten individual

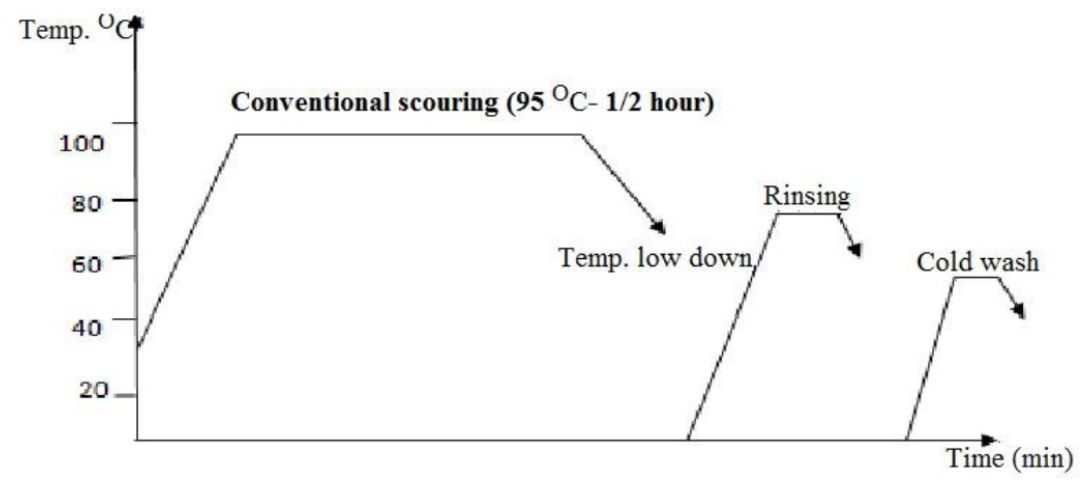

Figure 1: Scouring curve for cotton fabrics. 
readings were implemented for each fabric sample and the average of the readings was evaluated.

\subsection{Whiteness Index}

In this study, whiteness index is calculated, as:

$$
\text { CIE WI }=\mathrm{Y}+800\left(\mathrm{x}_{\mathrm{n}}-\mathrm{x}\right)+1700\left(\mathrm{y}_{\mathrm{n}}-\mathrm{y}\right)
$$

Where,

$$
\begin{aligned}
\mathrm{Y} & =\text { Lightness value, } \\
\mathrm{x} \text { and } \mathrm{y}= & \text { chromaticity coordinates of the sample, } \\
& \text { and }
\end{aligned}
$$

$x_{n}$ and $y_{n}=$ chromaticity coordinates of the light source used for the calculation.

\subsection{Color Strength}

Evaluation of dyeing was done by determination of $\mathrm{K} / \mathrm{S}$ using computer color matching system. Color strength of the woven fabrics under study was evaluated using SpectraScan 5100+ computer color matching system according to the following equation:

$$
\frac{K}{S}=\frac{(1-R)^{2}}{2 R}
$$

Where $\mathrm{K}$ and $\mathrm{S}$ are absorbing and scattering coefficients, and the reflectness of the dyed woven fabrics is represented by the $R$ value.

\subsection{Color Fastness of the Dyed Fabrics}

Color fastness can be defined as the resistance of color of the dyed fabrics to fade or bleed in case of various types of influences like as water, rubbing, washing, perspiration, acids, alkalis etc. In this study, color fastness of the woven fabrics was investigated. In accordance with ISO 105-C-10-2006, ISO 10-X 122002 and ISO 105-B2-02-2013 methods, color fastness to washing, rubbing and perspiration were measured.

\section{STATISTICAL ANALYSIS}

To examine the significant influences of spandex linear density and its draft ratio on whiteness index, color strength and color properties of the dyed woven fabrics, the analysis of variance (ANOVA) is considered the most efficient analysis to be used. The significance effect of each independent variable on the dependent ones was assessed using $p$-value, which ranges between 0.05 and 0.01 ,i.e. $0.01 \leq p$-value $\leq 0.05$. To predict each stretch fabric attribute at different levels of spandex linear density and draft ratios, a regression analysis was executed using SPSS software program. The regression relationship which correlates fabric properties with independent variables have the following non linear forms:

$$
Z=a+b X+c Y+d X Y+e X^{2}+f Y^{2}
$$

Where,

$Z=$ dependent variable (Color properties), i.e. whiteness index, K/S, --etc.

$\mathrm{X}=$ Spandex draft ratio, $\%$

$\mathrm{Y}=$ Spandex linear density, denier

$\mathrm{a}=$ Constant, and

b, c, d, e, and f, represent the egression coefficients.

Validation of the regression models were accomplished using calculating the value of the coefficient of determination, i.e. $\mathrm{R}^{2}$ value.

\section{RESULTS AND DISCUSSION}

\subsection{Effects on Whiteness Index}

Variations of whiteness index of the dyed woven fabrics according to the variations of both linear density of spandex monofilament and its linear density was illustrated in Figure 2. It was demonstrated that both independent variables have a profound influence on the whiteness index of the produced fabrics. It was determined that draft ratio and spandex linear density accounted for $27 \%$ and $53 \%$ respectively of the effects on fabric whiteness index.

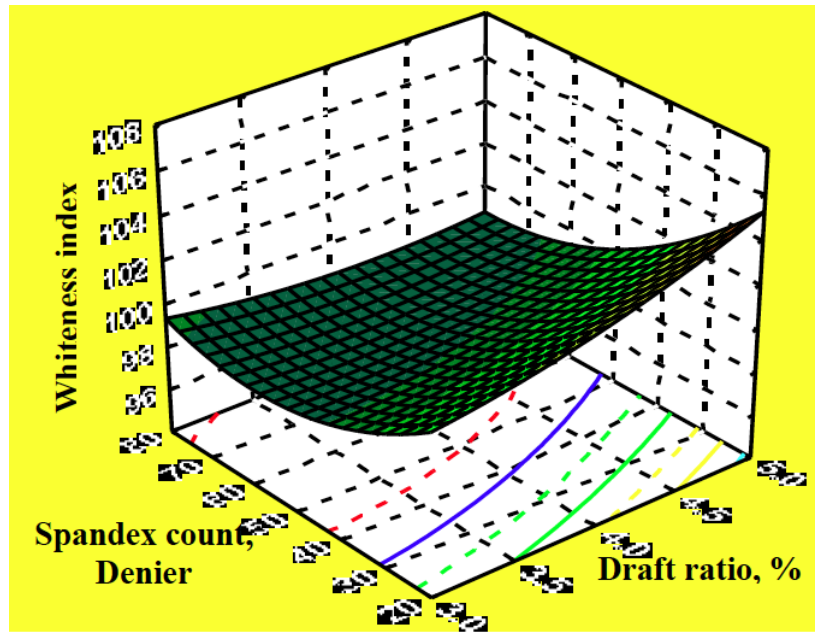

Figure 2: Response surface of the whiteness index of the dyed woven fabrics versus spandex draft ratio and count. 
From this figure, it is shown that whiteness index increase with the draft ratio. On the contrary, spandex linear density has a negative effect on whiteness index. The higher the spandex liner density is, the lower is the fabric whiteness index. Increasing draft ratio leads to decrease the amount of spandex in the woven fabric by about $51 \%$ to $66 \%$ depending on the spandex count, which in turn increases the amount of wrapped cotton fibers on the spandex monofilament as a core that causes increasing the whiteness index of the produced fabrics. Increasing spandex linear density leads to decrease the amount of cotton wrapped fibers about the core, i.e. spandex monofilament which leads to lowered fabric whiteness index.

The multiple non-linear regression model which correlates both spandex draft ratio and linear density to the whiteness index of the woven fabrics has the following form:

$$
\begin{gathered}
\text { Whiteness index }=105.3-1.6 X-0.12 y+0.5 X^{2} \\
-0.04 X Y+0.002 Y^{2}
\end{gathered}
$$

The coefficient of determination of the regression model was found to equal 0.84 which signifies that this model represents the data very well.

\subsection{Color Strength}

Variations of fabrics color strength according to the variation of both spandex draft ratio and linear density was depicted in Figure 3 . It was shown that independent variable have profound impact on the fabric color strength. It was estimated that draft ratio of spandex monofilament and linear density accounted for $10 \%$ and $65 \%$ respectively of the effects of the colors strength.

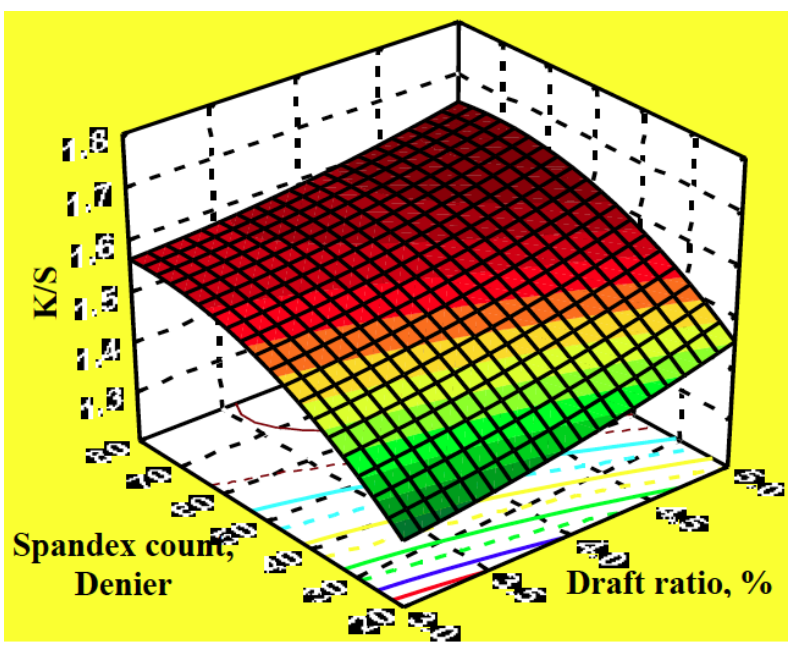

Figure 3: Response surface of color strength of the dyed woven fabrics versus spandex draft ratio and count.
It was noticed that as the spandex monofilament and linear density increases, the fabric color strength also increases. The increase in the spandex monofilament draft ratio from $3 \%$ to $5 \%$ leads to an increase of the K/S values by approximately $7 \%$. Also increasing linear density of spandex monofilament from 20 to 80 denier led to increases of fabric color strength by about $16 \%$. In general, increasing draft ratio or linear density of spandex causes the spandex monofilament to be finer which in turn increases the amount of cotton fibers wrapped around the core and finally increases the K/S values.

The regression model which correlates both linear density of spandex monofilament and its draft ratio to the color strength values of the dyed woven fabrics has the following non-linear form;

K/S value $=1.14-0.04 X+0.12 y+0.02 X^{2}-0.004 X Y$

It was determined that $\mathrm{R}^{2}$ value of this model was found to equal 0.91 . This means that experimental results were fitted data very well using this regression model.

\subsection{Washing Colorfastness}

The results of colorfastness values to washing of the dyed woven fabrics against the draft ratio and linear density of spandex monofilament were plotted in Figure 4. It was revealed that both independent variables have a significant impact on the colorfastness to washing at 0.05 significant level. It can be seen from this figure that both independent variables affect positively on the washing colorfastness. As the both variable increases the colorfastness to washing of the dyed fabrics swiftly increases.

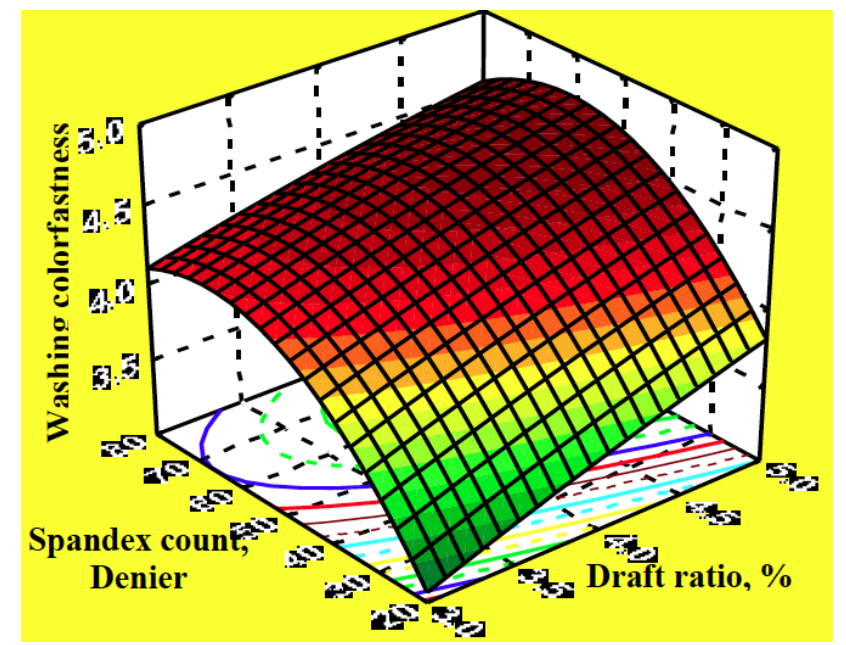

Figure 4: Response surface of the washing colorfastness of the dyed woven fabrics versus spandex draft ratio and count. 
It was estimated that spandex draft ratio and linear density accounted for $13 \%$ and $39 \%$ of the effects on the colorfastness to washing. The regression model which correlates both spandex draft ratio and linear density to the values of colorfastness to washing rating has the non-linear form;

$$
\begin{gathered}
\text { Colorfastness to washing rating }=0.21+0.64 X+ \\
0.08 y-0.03 X^{2}-0.003 X Y-0.05 Y^{2}
\end{gathered}
$$
0.84 .

It was estimated that the $R^{2}$ value of this model was

\subsection{Rubbing Colorfastness}

The results of rubbing colorfastness versus spandex drat ratio and its linear density was pictured in Figure $\mathbf{5}$. The statistical analysis revealed draft ratio has a significant impact on the rubbing colorfastness of the dyed woven fabrics; while spandex linear density was found to have no significant influence on the rubbing colorfastness. It was also proved that spandex draft ratio and linear density accounted for $10 \%$ and $6 \%$ respectively of the effects on the colorfastness to rubbing of the dyed woven fabrics.

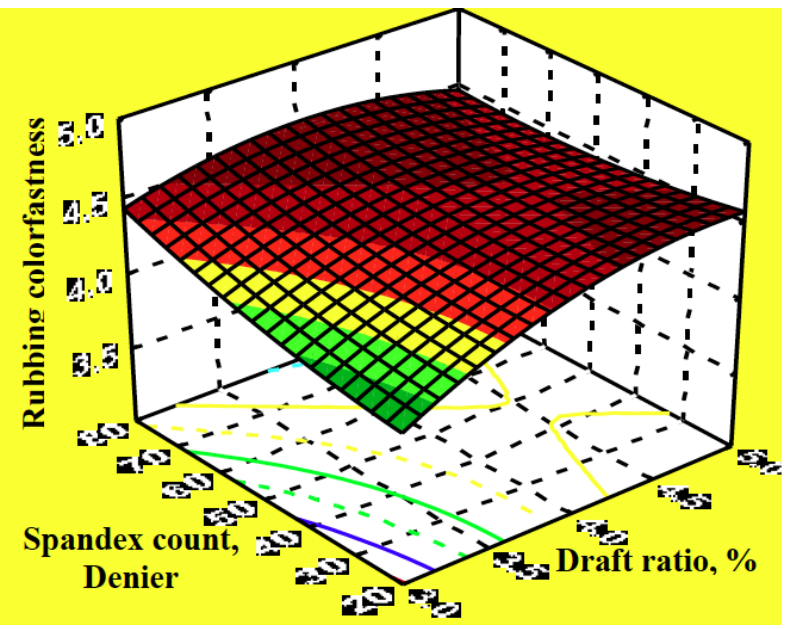

Figure 5: Response surface of the rubbing colorfastness of the dyed woven fabrics versus spandex draft ratio and count.

From this figure it can be noticed that as the both variables increases, the rubbing colorfastness of the dyed samples has the same trend. Increasing spandex monofilament drat ratio leads to an increase of rating of the rubbing colorfastness from 3-4 to $4-5$, while increasing spandex linear density leads to increase of the rating of colorfastness to rubbing by inferior or insignificant values.

The non- linear regression model which correlates both spandex draft ratio and linear density to the rating of rubbing colorfastness has the following form;

$$
\begin{aligned}
& \text { Colorfastness to rubbing rating }=0.33+1.7 X+ \\
& 0.014 y-0.17 X^{2}-0.005 X Y
\end{aligned}
$$

The $R^{2}$ value of this model was found to equal 0.79 .

\subsection{Perspiration Colorfastness}

Colorfastness of the dyed woven fabrics to acidic perspiration was evaluated against both the linear density and draft ratio of spandex monofilament. The experimental results of colorfastness to acidic perspiration were plotted in Figure 6. It is shown that both variables, i.e. draft ratio and linear density of spandex monofilament have a mighty influence on the colorfastness to perspiration of the dyed samples.

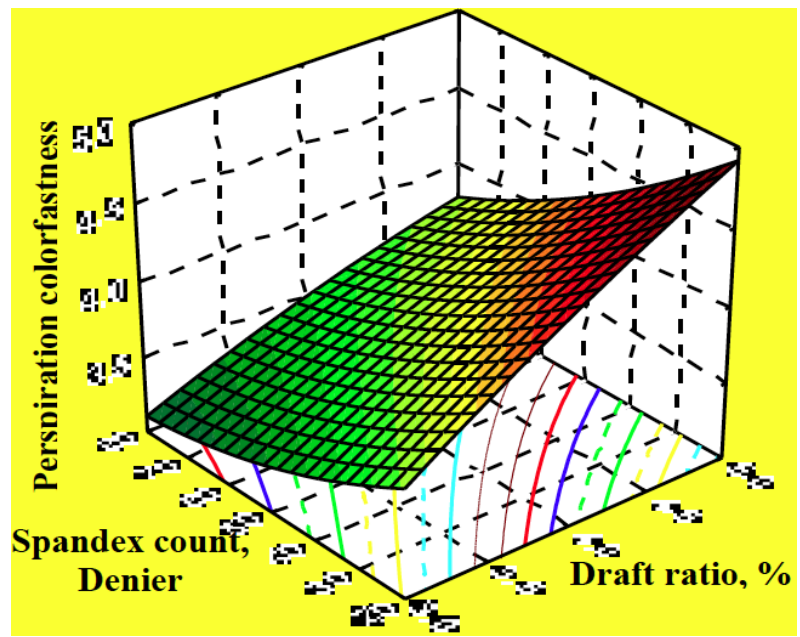

Figure 6: Response surface of the perspiration colorfastness of the dyed woven fabrics versus spandex draft ratio and count.

It was found that spandex monofilament draft ratio and linear density accounted for $18 \%$ and $12 \%$ respectively of the effects of the values of colorfastness to acidic perspiration. It can be observed from this figure that spandex draft ratio has a positive influence of the perspiration colorfastness, while spandex linear density was found to have a negative effect on the colorfastness to perspiration for the woven fabrics under study.

Increasing spandex monofilament draft ratio led to raise of the values of colorfastness to acidic perspiration of the dyed samples from rating 3 to 4-5. On the contrary, increasing linear density of spandex leads to reduction of colorfastness to perspiration rating from 4-5 to 3-4.

The regression model which correlates spandex draft ratio and linear density to the values of colorfastness to acidic perspiration has the following non-linear form; 
Colorfastness to acidic perspiration $=1.3+1.1$

$$
X-0.008 Y-0.05 X^{2}-0.005 X Y+0.001 Y^{2}
$$

The $R^{2}$ value of this model was found to equal 0.93 . This means that experimental result were fitted data very well using this regression model.

\section{CONCLUSION}

Color and fastness properties of stretchable woven fabrics were discussed extensively during this experimental study. These types of fabrics were woven from weft yarns containing spandex as a core with three different draft ratios and four different linear densities. The results throughout this study were statistically analyzed using ANOVA and regression statistical analysis techniques. The conclusion of this study can be sum up as follows:

- In general, dyed fabric properties, namely whiteness index, K/S values, and colorfastness to washing, rubbing and perspiration were all enhanced significantly with increasing the draft ratios of the spandex.

- Increasing linear density of spandex monofilament leads to a reduction of the whiteness index and colorfastness to perspiration of the dyed woven fabrics; while the remaining fabric color properties were enhanced significantly with the spandex linear density.

\section{REFERENCES}

[1] Hatice Kübra Kaynak. Optimization of stretch and recovery properties of woven stretch fabrics. Text Res J 2016; 1-11.

[2] Matsuo, T. Fundamentals of technologies for textile specialty products. Res J Text App 2004; 8(1): 77-87. https://doi.org/10.1108/rjta-08-01-2004-b009

[3] Almetwally AA, Mourad MM. Effects of spandex drawing ratio and weave structure on the physical properties of cotton/spandex woven fabrics. J Tex Inst 2014; 105(3): 235245.

https://doi.org/10.1080/00405000.2013.835092

[4] Bhortakke MM, Nishimura T, Matsuo. The Structure of polyester/cotton blended air-jet spun yarn. Text Res J 1999; 69(2): 84-89. https://doi.org/10.1177/004051759906900202

[5] Lin JH, Chang CW, Lou CW, Hsing WH. Mechanical properties of highly elastic complex yarns with spandex made by a novel rotor twister. Text Res J 2004; 74(6): 480484.

https://doi.org/10.1177/004051750407400603

[6] Ruppenicker GF, Harper RJ, Sawhney AP, Robert KQ. Comparison of cotton/polyester core and staple blend yarns and fabrics. Text Res J 2006; 59(1): 12-17. https://doi.org/10.1177/004051758905900102

[7] Merati AA, Konda F, Okammura M, Marui E. Filament pretension in core yarn friction spinning. Text Res J 1998; 68(4): 254-264. https://doi.org/10.1177/004051759806800403

[8] Bhat G, Chand S, Yakopson S. Thermal properties of elastic fibers. Thermochim Acta 2001; 367-368: 161-164. https://doi.org/10.1016/S0040-6031(00)00673-0

[9] Boliek JE. Elastane yarns 1950-2000. Chem Fib Int 2001; 50: 154-156.

[10] Sekan T, Yasemin K. Experimental investigation of effects of spandex brand and tightness factor on dimensional and physical properties of cotton/spandex single jersey fabrics. Text Res J 2008; 78(11): 966-976.

https://doi.org/10.1177/0040517507087685

[11] Mukhopadhyay A, Sharma IC, Mohanty A. Impact of lycra filament on extension and recovery characteristics of cotton knitted fabric. Ind J Fib Tex Res 2003; 38: 423-430.

[12] Sajn D, Geršak J, Bukošek V. A study of the relaxation phenomena of fabrics containing elastane yarns. Paper presented at the 2nd International Textile, Clothing and Design Conference - Magic World of Textiles; Dubrovnik, Croatia 2004.

[13] Ceken F. Some Investigations of the Dimensional Properties of Knitted Fabrics Containing Different Materials (Unpublished doctoral thesis). Ege University, Izmir 1995.

[14] Meriç B, Gürarda A. Proceeding of the $X I^{\text {th }}$ Textile and Leather Romanian Conference. lasi: Performantica Publishing House 2002; pp. 17-19.

[15] Bayazit MA. Dimensional and physical properties of cotton/spandex single jersey fabrics. Text Res J 2003; 73(1): 11-14.

https://doi.org/10.1177/004051750307300102

[16] Almetwally AA, Idrees HF, Hebiesh AA. Predicting the tensile properties of cotton/spandex core-spun yarns using artificial neural network and linear regression models. J Tex Inst 2014; 105(11): 1221-1229. https://doi.org/10.1080/00405000.2014.882043

[17] Ibrahim NA, Amr A, Eid BM, Almetwally AA, Mourad MM. Functional finishes of stretch cotton fabrics. Carbohydr Polym 2013; 98: 1603-1609.

https://doi.org/10.1016/j.carbpol.2013.07.047

[18] Almetwally AA, Mourad MM. Effects of spandex drawing ratio and weave structure on the physical properties of cotton/spandex woven fabrics. J Tex Inst 2014; 105(3): 235245.

https://doi.org/10.1080/00405000.2013.835092

[19] Almetwally AA, Eid YM, Alsalmawy A. Performance of woven fabrics containing spandex. Ind Tex J 2010; 41(5): 39-42.

[20] Mourad MM, Elsalmawy A, Almetwally AA. Core spun yarn and the secret behind its popular appeal. Text Asia 2010; 41(8): 28-32. 